\title{
Ordenanzas sobre el regimiento del cabildo jerezano
}

\author{
Juan Abellán Pérez *
}

Desde que Alfonso XI implantara el Regimiento en Jerez en $1345^{1}$ hasta la promulgación de las Ordenanzas objeto de este estudio en $1429^{2}$, el progresivo fortalecimiento del grupo de los regidores había ido extendiendo su radio de acción, acaparando a través de parientes y amigos los oficios de la administración local, propios de la población pechera; su actuación, al menos desde 1411, se vio controlada y fiscalizada por los jurados ${ }^{3}$. Este grupo compuesto por dieciocho miembros a inicios

* Universidad de Cádiz.

1 El documento se conoce a través de su confirmación por Juan II en 1429 (Archivo Municipal de Jerez, Cajón 9, núm. 40). Fue publicado por Bartolomé Gutí́rrez: Historia de la muy noble e muy leal ciudad de Jerez de la Frontera, Jerez 1886, II, 209. De él lo toma fragmentado H. SANCHO DE SOPRANIS: Historia social de Jerez de la Frontera al fin de la Edad Media. I. Vida material, Jerez 1959, I, 6. Hacen referencia a este documento, entre otros, M. A. LADERo Quesada: Andalucía en el siglo xv. Estudios de Historia Política, Madrid $1973,84$.

2 AMJ Cajón 9, núm. 40 .

3 A diferencia de los concejos de Sevilla y Córdoba, que con anterioridad al 1411 disponían de una cantidad para el envío de un jurado a la Corte a informar al Rey del estado de estas ciudades, Jerez, pese a regirse por el mismo fuero y ordenamientos que Sevilla, carecía de esta asignación anual hasta que en la minoría de Juan II sus tutores la otorgaron con cargo a los propios de la ciudad (Actas Capitulares de 1436, fols. 256v-257r); no se conservan muchos de estos informes, pero los suficientes para ver que predominan las denuncias sobre el mal gobierno de los alcaldes mayores y regidores, fraude en la entrega de los oficios anuales, apropiación indebida de los recursos del concejo, derramas... Sobre esta problemática puede verse J. ABELLÁN PÉREZ: “Conflicto en el concejo xericiense. Nombramiento de jurados en 1436", Estudios de Historia y de Arqueología Medievales, VIIVIII (en prensa). 
del siglo $\mathrm{XV}$, dos por colación ${ }^{4}$, comienza mediante sus informes anuales al Rey, a denunciar el mal gobierno de los alcaldes mayores y regidores, determinando la constante y pesada carga económica que suponía la presencia de corregidores y pesquisidores ${ }^{5}$; sin embargo, aunque pudo influir, no fue este estamento el promotor de las Ordenanzas de 1429 sino el de los propios regidores.

Los primeros pasos para su consecución, arrancan de la petición que el regidor Antón Martínez de Hinojosa, en nombre de Jerez, presentó en el Consejo Real, solicitando de Juan II la confirmación del privilegio alfonsí expedido en Sevilla el 1 de enero de 1345, en el que se establecia el trecenazgo, de cuyo seno, anualmente, debían salir dos alcaldes mayores con poder de asistencia a los cabildos y ayuntamientos «... como alcaldes, más no como trece, e conplido el tiempo que an de ser alcaldes que sean de los treze..." ; facultad para que vieran «...los fechos de la villa, e pongan los oficiales los que vieren que cunplen e que puedan poner cada año los dos de ellos por alcaldes mayores... e los otros ofiçiales que los pongan de los otros vezinos de la villa, que ninguno de estos treze"que no ayan ningund otro ofiçio en la villa ...” ?

La orden que Juan II dio al canciller y resto de oficiales de la tabla de sellos para la confirmación fue expedida en Valladolid el 6 de mayo

4 Aunque se viene afirmando que a comienzos del siglo XV este estamento estaba constituido por nueve jurados, uno por cada colación, la realidad es muy distinta si se contabilizan los miembros de este grupo que asisten a las asambleas locales. Asi, en los fragmentos de las Actas Capitulares de 1409, las más antiguas que se conservan, el número es de 12 y en las de 1.410,18 (Antón Ruiz de Busto, Pedro Fernández, Pascual Gil, Juan Esteban de Torrecilla, Fernando Gil de Aroche, Juan Ortiz de Natera, Juan Esteban de Valdespino, Pedro Alfonso de Jaina, Benito Sánchez de Perales, Juan González, Francisco Martínez, Antón Martínez, Juan Esteban de Cuenca, Alfonso Martínez de Trujillo, Alfonso Jiménez, Lope Rodríguez, Antón Ruiz), cifras que se desorbita en 1447, llegándose a registrar hasta 21 .

5 Las Actas Capitulares de 1411 a 1415 no se conservan, ni siquiera fragmentos, por ello, no sabemos si en esos años hubo corregidor o pesquisador en Jeréz; sin embargo, sabemos que en 1416 fue nombrado corregidor el doctor Pedro González del Castillo, en 1419 los bachilleres Alvaro Martínez de Belmonte y Rui Fernández, en 1426 Gonzálo Sánchez de Pareja, en 1427 Juan Rodríguez de Sevilla, en 1428 Alvaro del Castillejo, en 1430 Juan Alfonso de Morgaes, en 1431, pesquisador, Pedro Fernández de Zamora, en 1432 como corregidor Pedro Maldonado que continuó en 1433, y así una larga lista.

${ }_{6}$ AMJ. Vitrina 1. Se trata de un traslado sacado en Jerez de la Frontera el martes 16 de noviembre de 1501 .

7 Ibidem nota anterior. H. Sancho de Sopranis: Ob. cit., 6. 
de $1429^{8}$; haciéndose efectiva por un privilegio rodado, otorgado también en Valladolid el 20 de junio del mismo año ${ }^{9}$.

Con la petición enviada a la corte con Antón Martínez de Hinojosa se pretendía la regulación del funcionamiento del cabildo xericiense, que desde la implantación del regimiento en el siglo XIV se había ido alterando, provocando los intereses personales, familiares o de grupos «...muchas diuisiones, debates e contiendas en el regimiento e en el dar de los ofiçios ..." ${ }^{10}$, llegando a ser muy frecuente, casi constante, que los alcaldes mayores con dos o tres miembros del estamento de los regidores asumieran la dirección del cabildo y, en consecuencia, el gobierno de la ciudad, dejando al margen del mismo «... a los otros regidores e ofiçiales de la dicha çibdad que son la mayor e mas sana parte de aquellos que han de ver e ordenar fazienda..." ${ }^{11}$.

El deseo de acabar con las alteraciones que se vivian en la ciudad de Jerez y que aquélla volviera a ser regida y gobernada con justicia, a instancia de Antón Martínez, Juan II hubo información de las Ordenanzas de Sevilla, por donde se regían, cuya información se plasmaría en una nueva ordenanza sobre el modo en que debía regirse el cabildo jerezano, expedida en el monasterio de Santa María de Fresdelval el 12 de octubre de 1429; dicho documento, aunque hace referencia a dos tipos de cabildos, el integrado por los alcaldes mayores, alguacil mayor, regidores y jurados que debía reunirse en asamblea ordinaria los lunes, miércoles y viernes de cada semana y el cabildo de los regidores que debía celebrarse el sábado, se dedica fundamentalmente al primero, pese a que en

\section{Vitrina 1}

8 Inserta en el privilegio rodado expedido en Valladolid el 20 de junio de 1429. A.M.J.

9 Ibidem.

10 Ibidem nota anterior, Este fue uno de los aspectos que determinó la reforma municipal llevada a cabo en Sevilla y Toledo en 1411 por el infante don Fernando de Antequera en 1411, y que suponemos que también debió producirse en Jerez. Refiriéndose a Toledo dice el profesor Sáez: «... los encargados de la cosa pública antes antendían a sus particulares intereses que a los de la ciudad, y eran frecuentes el abuso de autoridad, el cohecho, el soborno, la prisión sin motivo, el robo descarado y toda clase de arbitrariedades cometidas por los mismos que debian dar ejemplo de equidad». E. SÁEZ: «El Ordenamiento dado a Toledo por el infante don Fernando de Antequera, tutor de Juan Il", $A H D E, X V$, separata.

11 Ibidem. Los alcaldes mayores no se limitan a presidir el cabildo, salvo cuando hay corregidor, y a emitir su voz y voto. Los abusos de autoridad les lleva a extremos de no respectar la decisión de la mayoría concejil, no permitiendo, en el caso de otorgamiento de oficios, que los elegidos hiciera el juramento preceptivo si ellos no estaban conformes. 
este no todos sus miembros tienen derecho a voto -alguacil mayor y jurados-, el número de votantes es mayor que el segundo.

El derecho a voto y su regulación es uno de los puntos más importantes de cuantos se recogen en las Ordenanzas. Los dos alcaldes mayores tenían respectivamente voz y voto; salvo cuando había corregidor en la ciudad como ocurre en 1429, en que este oficial real asumia los oficios de la justicia, quedando reducidos los votos a uno, derechos que no era extensible a los alcaldes que pudiera poner, excepto si se ausentaba de la ciudad; en este caso, su voz y voto recaía en uno de sus alcaldes, designado por ellos ${ }^{12}$.

Otro de los aspectos regulados es la convocatoria de cabildo y la validez de sus acuerdos. En principio, la Ordenanza fija los lunes, miércoles y viernes como días de la semana para la celebración del ayuntamiento, obligando a todos sus miembros con derecho a voto -alcaldes y regidores- sin que previamente tuvieran que ser llamados a cabildo; sin embargo, el absentismo unas veces y otras las ausencias de la ciudad por causas de indole diversa o ambas a la vez, testimonian la escasa presencia y participación en el gobierno local; ello, determinaría, como medida que evitara la paralización de la administración que en las reuniones ordinarias de la asamblea concejil, lo que acordaran los presentes o las dos partes de ellos tuviera validez, siempre que las dos partes de los presentes no fuera menor de cuatro regidores. Esta disposición afecta a asuntos de carácter menor, ya que los temas de mayor trascendencia como eran el otorgamiento de los oficios, cuestiones monetarias o constitución de procuradores o mensajeros para la Corte, el número de voces se eleva a siete regidores, en teoría la mitad más uno, puesto que en la realidad el número de regidores que se recogen en las asistencias a cabildo es mayor de trece. Si para tratar estos temas calificados de importantes $u$ otros de menor interés se requería incrementar el número de sesiones semanales, es decir, celebrar cabildos extraordinarios, es entonces cuando la Ordenanza establece que los miembros del cabildo, tanto los presentes en la ciudad como los que se encontraban fuera de ella hasta una legua alrededor, debían ser llamados por el

12 Un análisis minucioso de las Actas Capitulares permite comprobar que este principio casi nunca se cumple en los términos expuestos en las Ordenanzas. El escribano del concejo se limita a registrar los miembros de la asamblea, con voz o con voz y voto, presentes, y los que se van incorporando o ausentando durante el desarrollo de la sesión, y algunas veces las alternativas presentadas a cada uno de los temas a tratar y los resultados de las votaciones, cuando se producen. 
pregonero público, al menos con veinticuatro horas de antelación, respetándose según los asuntos a tratar los porcentajes establecidos.

El tercer punto a destacar de las Ordenanzas es el que da sentido al hecho material de las Actas Capitulares, la presencia en estas reuniones, ordinarias o extraordinarias del escribano del concejo. Sus funciones se establecen con gran claridad, escribir por registro los oficiales presentes y los ausentes, recogiendo los nombres de los que consentían en temas tratados y los que no ${ }^{13}$.

Junto a este cabildo como se ha apuntado, existió el de los regidores, aunque su funcionamiento lo desconocemos, así como su efectividad. Su cometido era decidir si lo tratado en cabildos, ordinarios o extraordinarios, era en perjuicio de la ciudad para informar al Rey; es, por tanto, similar al cabildo de jurados, si bien sus informes no tienen una periodicidad como el de los jurados que era anual.

La entrada en vigor de esta normativa, así como su efectividad es imposible de conocerla ante la inexistencia de las Actas Capitulares de 1429; de hecho, tampoco sabemos la fecha de su presentación en el cabildo, pero como muy pronto debió de efectuarse en el mes de noviembre, cuando faltaba un mes para el inicio de la elección de los alcaldes mayores y oficiales menores; del año 1430 tampoco se conservan las Actas Capitulares, a excepción de un breve cuadernillo de gran importancia, ya que en él se recogen unas ordenanzas realizadas en la reunión que la asamblea local realizó el miércoles 22 de febrero, estando reunidos en la casa del cabildo diez regidores ${ }^{14}$ y trece jurados ${ }^{15}$, cuya temática está en íntima relación con la problemática apuntada por el regidor Antón Martínez, las divisiones surgidas en el seno del cabildo a la hora de «dar de los ofiçios». El primero de sus puntos es un compro-

13 De esta cifra, siete estuvieron presentes en el acto de su aprobación (Pedro Fernández Pezano, Antón Martínez de Hinojosa, Gonzalo Núnez, Fernando Alfonso, Fernando de Villavicencio, Juan Ortiz de Natera y Pedro Fernández de Vargas), los restantes fueron Juan Sánchez de Bivanco y Alfonso de Vanades, quienes en ese rnismo día juraron esta ordenanza en sus casas, y Juan García de Nátera que lo hizo el día 24 de febrero en la escribanía de Diego González. Aunque el número de regidores fue importante, sesiones correspondientes a otros años, testimonian o manifiestan la negativa de otros.

${ }_{14}$ Juan López de Grejal, Diego Rodríguez de Nátera, Diego González, Diego Alfonso de Jaina, Alfonso Fernández de Herrera, Guiraldo Gil, Diego Rodríguez Pavón, Bartolomé de las Casas, Mateo Bernal, Diego Martínez de Trujillo, Juan Benítez, Alfonso García de Cuenca y Fernando Alfonso de Herrera.

15 AMJ A.C. 1430 , fols. $14 \mathrm{v}-15 \mathrm{v}$. 
miso de todos los miembros de la asamblea de establecer lazos de amistad, de ser «... buenos e leales e verdaderos amigos unos a otros, guardando el seruiçio del Rey e el pro e bien de esta çidat e de la republica de ella, e de se guardar sus onrras los unos a los otros, e los otros a los otros...». Esta debía ser, sin lugar a dudas, la primera vía para solicitar a Juan II la devolución de los oficios de la justicia anulados por la presencia de corregidor ${ }^{16}$; la paz y el orden del cabildo, permitía al concejo suplicar al Rey la necesidad de suspender a este oficial, concretado así: «Iten ordenaron todos los sobredichos de suplicar la merçet del dicho señor Rey que la su señoría les mande proueer e prouea de los ofiçios de alcalldias mayores e alguazilago de esta çibdat segund que los auian ante que su merçet proueyese de corregimiento, e auidos los dichos ofiçios los ayan en esta menera, las alcalldias mayores los dichos corregidores e el alguaziladgo que lo repartan por las collaçiones segund que lo auian costunbrado ${ }^{17}$.

De los catorce puntos que se tratan, dos son los que queremos destacar. El primero de ellos la aplicación de la normativa de Alfonso XI sobre los alcaldes mayores, recogida en las Ordenanzas de 1429, que aquellos que en el año que fueran alcaldes no tuvieran «tierra ni bos por regidores" y que no estuvieran presentes ni dieran su voz en las colaciones donde moraban, tanto en la "exleçion de los oficios e repartimientos de los pechos e derramas que se repartieren".

Pese a esta regulación del cabildo y los buenos propósitos de los oficiales jerezanos, recogidos en las peticiones elevadas a Juan II y en la documentación concejil, se puede fácilmente comprobar su incumplimiento, predominando por encima de todo sus intereses antes que el buen gobierno de la ciudad.

16. No conocemos el nombre del corregidor de este año, pero los oficios de la justicia continuaron suspendidos temporalmente durante el año 1430 en que fue corregidor Juan Alfonso de Morgaes y en la primera mitad de 1431.

17 lbidem nota 15. 


\section{APÉNDICE DOCUMENTAL}

1429-X-12.-Santa María de Fresdelval, monasterio.

Juan II notifica al concejo de Jerez las ordenanzas por las que debía regirse en el cabildo

(A.M.J. Cajón 9, núm. 40)

Don Juan por la graçia de Dios rey de Castilla, de Leon, de Toledo, de Gallizia, de Seuilla, de Cordoua, de Murçia, de Jahen, del Algarues, de Algezira, señor de Viscaya, de Molina. Alconçejo, corregidor, alcaldes, alguazil, caualleros, escuderos, regidores, jurados, omes buenos de la çibdad de Xerez de la Frontera que agora son o seran de aqui adelante, e a qualquier 0 a qualesquier de vos a quien esta mi carta fuere mostrada o el treslado de ella signado de escriuano publico, salud e graçia.

Sepades que vi una carta que el Rey don Alfonso que Dios perdone, mi trasbisabuelo, mando dar e dio a esa dicha çibdad para el regimiento de ellas, el tenor de la qual es este que se sigue:

(Inserta de Alfonso XI, dada en Sevilla, 1-I-1345)

E agora sabed que Anton Martinez de Hinojoda, regidor de la dicha çibdad presento ante mi en el mi consejo una petiçion en que diz que en cada un año recreçen en esa dicha çibdad muchas diuisiones, debates e contiendas en el regimiento, e en el dar de los ofiçios de ellas, por que el corregidor e los alcaldes mayores quando no ay corregidor con dos o 
tres regidores diz que dan los dichos ofiçios e facen otras cosas que tañen al regimiento de la dicha çibdad, e que no se fazen mençion de los otros regidores e ofiçiales de la dicha çibdad que son la mayor e mas sana parte de aquellos que han de ver e ordenar fazienda, por que de aqui adelante çesasen los dichos debates e contiendas e la dicha çibdad fuese regida e gouernada en justiçia, segund que cunple a mi seruiçio, $e$ a pro e bien de dicha çibdad e vezinos e moradores de ella çerca de lo qual me pidio por merçed que mandase auer ynformaçion de las hordenanças de la dicha çibdad de Seuilla, por donde se rigen, por que de ellas se podria dar una orden a regimiento de esa dicha çibdad, e yo touelo por bien.

Por ende por quitar muchas dudas e ynconuenientes que podrian recreçer en la dicha çibdad en lo susodicho para agora e para aqui adelante entendiendo que asi cunple a mi seruiçio e al prouecho e bien publico de la dicha çibdad conformandome en parte con algunas de las hordenanças, usos e costunbres que çerca de esto tiene la dicha çibdad de Seuilla ordepno e mando que de aqui adelante se guarden las hordepnaças siguientes:

Primeramente ordepno e mando que los alcaldes mayores de la dicha çibdad que son o fueren de aqui adelante que tengan cada uno de ellos una boz en cabildo como uno de los treze regidores de la dicha çibdad, e no mas, e si acaeçiere que este ay en la çibdad por mi mandado que tenga los ofiçios de las justiçia, alcaldes mayores e alguazil, segund que agora esta que el tal corregidor en cabildo aya una boz como uno de los dichos treze regidores, e no mas, e que en su presençia los alcaldes por si pusiere no ayan boz alguna, e absentandose el dicho corregidor que los alcaldes que el por si en su lugar dexare que aya una boz e no mas, amos juntos, e qualquier de ellos que el declarare que tenga su boz.

E otrosy ordepno e mando que en cada semana, lunes, miercoles, viernes se ayunten todos los dichos ofiçiales, alcaldes mayores, e corregidor, e regidores en cabildo en el logar acostunbrado, no enbargante, que para ello espeçialmente no sean llamados, e lo que fizieren los dichos ofiçiales o las dos partes de los presentes, asi ayuntados en los dichos dias señalados que vala como si todos los dichos ofiçiales lo fizyesen, seyendo juntos con tanto que las dos partes de los presentes no sean menos de quatro regidores, pero quiero e es mi merçec que esto no aya logar en el dar de los ofiçios e del dinero e en fazer e contetuyr procuradores o mensajeros para ante $\mathrm{mi}$, ca en esto mi merçed 
e voluntad es que no sean menos de siete bozes de regidores, e si acaesçiere que en quatro dias fuere neçesario e conplidero a mi seruiçio e al bien publico de la dicha çibdad de se ayuntar, e hordepno e mando que todos los dichos ofiçiales que fueren presentes en la dicha çibdad, e los que estouieren una legua enrrededor de la dicha çibdad que sean llamados por su ofiçial portero publico para ello diputado de ante dia, e asi llamados lo que fuere fecho en concordia por las dos partes de los presentes que ay vinieren al dicho cabildo que vala e sea firme como si todos fuesen presentes e concordes, tanto que no sean menos que quatro bozes de regidores de los que asi fueren presentes, segund dicho es, saluo si fuere para dar dineros algunos o para proueer de ofiçios o enbiad procuradores e mensajeros para la mi corte, ca en estos casos mi merçed e voluntad es que no sean menos de siete bozes de regidores como dicho es.

Yten, ordepno e mando quando se ouieren de dar algunos ofiçios o enbiar procuradores o mensajeros a mi o a la mi corte o a dar dineros que sean llamados de ante dia espeçialmente todos los ofiçiales que estouieren en la dicha çibdad e una legua enrrededor, en qualquier dia que se ouiere de fazer cabildo, aunque sea en los dichos dias diputados e señalados de lo que fuere fecho en otra manera que no vala.

Yten, hordeno e mando que los dichos regidores puedan por sy fazer cabildo en cada dia de sabado de cada una semana syn estar a ello presentes los alcaldes mayores e alguazil o el corregidor o jurados para ver lo que fazen los dichos corregidor $o$ alcaldes e alguazil e sus lugarestenientes e el alamin de la dicha çibdad, si es agrauio e prejuyzio de la dicha çibdad de algunos de los vezinos e moradores de ella para que lo puedan querellar a mi merçed e procurar que se enmienden por via de orden de derecho, pero es mi merçed que en los tales cabildos que los dichos regidores fizieren syn los dichos corregidor o alcaldes e alguazil e jurados que no puedan fázer ni ordepnar otras cosas, saluo en lo susodicho.

Yten, hordepno e mando que el escriuano del conçejo de la dicha çibdad que sea tenido e obligado de escreuir por registro en los dias que se fizieren cabildo en la dicha çibdad, quales ofiçiales son los que alli son presentes e consyenten en lo que se fazen e ordepna en el dicho cabildo por la dicha çibdad, e quales son los que contradizen, declarandolos por sus propios nonbres por que asy escripto yo sepa e sea ynformado de lo que el faze o deue fazer en la dicha çibdad, e yo prouea sobre todo como cunple a mi seruiçio, e las quales dichas hordenanças 
a cada una de ellas suso en esta mi carta encorporadas entendiendo que cunple a mi seruiçio quiero e mando que sean auidas por ley en esa dicha çibdad para agora e para sienpre jamas, e las guardedes e cunplades, no enbargante qualquier mandamiento en contrario de esto fuere dado o fecho por el corregidor o alcalldes mayores de la dicha çibdad que por tienpo fueren, e por qualquier de ellos.

Porque vos mando que veades las dichas mis hordenanças suso encorporadas e las cunplades e guardedes e fagades guardar e conplir en todo e por todo segund que en ellas se contiene, agora e de aqui adelante no enbargante qualquier uso e costunbres fasta aqui en contrario de esto sea o adelante quieran yntreduzir, ca yo por esta mi carta la reuoco e anulo e quiero que no vala e las fagdes apregonar publicamente por las plaças e merados, en en los lugares acostunbrados de esa dicha çibdad por que venga a notiçia de todos los alcaldes, e regidores, e jurados, ofiçiales, omes buenos de la dicha çibdad, e no puedan de ello pretender ynorançia diziendo que lo no suplieron, e los unos ni los otros no fagades ni fagan ende al por alguna manera so pena de la mi merçed e de diez mill marauedis a cada uno de vos por quien fincare de lo asy fazer e conplir para la mi camara, e demas por qualquier o qualesquier de vos por quien fincare de lo asi fazer e complir mando al ome que esta mi carta mostrare o el dicho su treslado sygnado como dicho es que vos enplaze que parescades ante mi en la mi corte, doquier que yo sea del dia que vos enplazare fasta quinze dias primeros syguientes so la dicha pena a cada uno a dezir por qual razon no conplides mi mandado, e mando so la dicha pena a qualquier escriuano publico que para esto fuere llamado que dende al que vos la mostrare testimonio sygnado con su sygno por que yo sepa en como se cunple mi mandado, e de esto mande dar esta mi carta escripta en pargamino de cuero e firmada de mi nobre e sellada con mi sello de plomo pendiente en filos de seda.

Dada en el monasterio de Santa Maria de Fresdelval, doze dias de mes de ctubre, año del naçimiento de nuestro saluador Jhesuchristo de mill mill e quatroçientos e veynte e nueve años. Yo el Rey. Yo Gomez Mendez de Deça, la fiz escreuir por mandado de nuestro señor el Rey. 